\title{
APLICAÇÃO DE DEJETO SUÍNO E ESTRUTURA DE UM LATOSSOLO VERMELHO SOB SEMEADURA DIRETA ${ }^{1}$
}

\author{
Pig slurry application and structure of a red latosol under no tillage \\ Cesar Alessandro Oliveira Arruda², Mauricio Vicente Alves ${ }^{3}$ Álvaro Luiz Mafra², \\ Paulo Cezar Cassol ${ }^{2}$, Jackson Adriano Albuquerque ${ }^{2}$, Julio Cesar Pires Santos ${ }^{2}$
}

\begin{abstract}
RESUMO
Objetivou-se, neste trabalho, estimar o efeito da aplicação de doses crescentes de dejetos suínos, em atributos físicos do solo. O experimento localizado em Campos Novos, SC, foi conduzido num Latossolo Vermelho Distroférrico, no delineamento experimental em blocos casualizados, com quatro repetições, com os tratamentos: testemunha (0); adubo solúvel (AS); combinação dejeto e adubo solúvel (DS); dejeto líquido suíno aplicado nas doses de 50, 100 e $200 \mathrm{~m}^{3} \mathrm{ha}^{-1}$. Desde 2001 foi cultivado milho e aveia preta, sob sistema de semeadura direta. A amostragem do solo foi realizada em janeiro de 2006, nas camadas de 0-5; 5-10; 10-20 cm de profundidade, para determinação de carbono orgânico, densidade, estabilidade de agregados, macroporos, microporos e porosidade total. A aplicação de dejeto suíno nas doses de 50 e $100 \mathrm{~m}^{3} \mathrm{ha}^{-1}$, reduziu a estabilidade de agregados do solo em relação à testemunha sem adubação. Os demais atributos físicos do solo e o teor de C orgânico não foram modificados pelos tratamentos, indicando que o uso agrícola do dejeto suíno, nas condições estudadas, mantém a qualidade física do solo.
\end{abstract}

Termos para indexação: Adubação orgânica, descarte de dejetos, estabilidade de agregados, esterco.

\section{ABSTRACT}

The objective of this study was to assess the effects of crescent doses of pig slurry on physical soil properties. The experiment is carried out in Campos Novos, SC, southern Brazil, on a red distroferric latosol, with a completely random blocks experimental design and four replicates, with the following treatments: control (0); soluble fertilizer (SF); combination of pig slurry and soluble fertilizer (SS); pig slurry applications of 50,100 and $200 \mathrm{~m}^{3} \mathrm{ha}^{-1}$. Since 2001, maize and black-oat were cultivated under no tillage soil management. Soil samples were collected in January 2006, from 0-5; 5-10; 10-20 cm deep, to analyze organic carbon, soil density, aggregate stability, macro, micro and total porosity. The application of 50 and $100 \mathrm{~m}^{3} \mathrm{ha}^{-1}$ of pig slurry decreased soil aggregate stability, in relation to the control treatment with no fertilization. The other physical properties and organic carbon contents had no effect on the treatments, demonstrating the pig slurry application under these tested conditions maintains the soil physical quality.

Index terms: Aggregate stability, pig manure, slurry discharge.

(Recebido em 28 de abril de 2008 e aprovado em 17 de março de 2010)

\section{INTRODUÇÃO}

O avanço tecnológico na produção de suínos despertou interesse crescente em confinar animais em todas as fases do ciclo produtivo, aumentando a produtividade por unidade de área e de tempo. Essa concentração de animais trouxe como consequência alta produção de dejetos, sendo um desafio seu adequado aproveitamento para evitar problemas ambientais (Oliveira, 1993). Um dos destinos desses resíduos consiste na adição ao solo como fertilizante o que pode trazer benefícios às culturas pela adição de nutrientes e matéria orgânica (Scherer et al., 1995).

A aplicação de resíduos orgânicos no solo é uma das formas de repor os elementos extraídos pelas culturas, complementando ou substituindo os fertilizantes minerais recomendados nos programas de adubação. Nesse sentido pesquisas são realizadas para avaliar as modificações químicas, tanto em termos de disponibilidade de nutrientes, quanto sua mobilidade no solo e ambiente. Essas alterações dependem das condições edáficas, do manejo do solo e das culturas, bem como das doses e frequência de aplicação do dejeto (Jokela et al., 2009). Por outro lado, pouco se conhece acerca das influências de aplicações de altas doses de dejetos sobre atributos físicos do solo.

A estrutura do solo e sua funcionalidade dependem dos constituintes do solo, de seu arranjo e estabilidade, o que repercute nas trocas de fluidos e na atividade biológica. A aplicação de dejetos animais pode assim, alterar a condição estrutural do solo, o que seria evidenciado por

${ }^{1}$ Parte da Dissertação de Mestrado do primeiro autor, apresentado à Universidade do Estado de Santa Catarina, Centro de Ciências Agroveterinárias UDESC/CAV

2Universidade do Estado de Santa Catarina/UDESC - Lages, SC

Universidade Federal de Lavras/UFLA - Cx. P. 3037 - 37200-000 - Lavras, MG - mauriciovicente@gmail.com 
modificações na quantidade, continuidade e tamanho dos poros do solo (Ribeiro et al., 2007). Influenciam também o desenvolvimento das plantas, em virtude de alterar a aeração, a resistência à penetração das raízes, e consequentemente a absorção de água e nutrientes (Mosaddeghi et al., 2009). Essas alterações variam conforme o solo e atuam conjuntamente com atributos biológicos e químicos na determinação dos impactos dos dejetos no ambiente (Seganfredo, 2007).

Objetivou-se, neste trabalho, avaliar o efeito da aplicação de doses crescentes de dejetos suíno em atributos físicos ligados à estrutura de um Latossolo Vermelho distroférrico, em sistema de semeadura direta, servindo como referencial para o aproveitamento agrícola desse resíduo, sem comprometer a qualidade do solo.

\section{MATERIAL E MÉTODOS}

A área experimental localiza-se em Campos Novos, SC, com coordenadas 51 $21^{\prime} 48^{\prime \prime} \mathrm{W}$ e $27^{\circ} 23^{\prime} 33^{\prime}$ 'S , e altitude média de 908 metros, com clima mesotérmico úmido com verões amenos, $\mathrm{Cfb}$, segundo Köppen. O solo é um Latossolo Vermelho Distroférrico, tendo como material de origem o basalto (Empresa Brasileira de Pesquisa Agropecuária-Embrapa, 2004). A distribuição granulométrica na camada de 0 a $20 \mathrm{~cm}$ de profundidade, analisada no tratamento testemunha, é representada por $48 \mathrm{~g} \mathrm{~kg}^{-1}$ de areia, $271 \mathrm{~g} \mathrm{~kg}^{-1}$ de silte e $681 \mathrm{~g} \mathrm{~kg}^{-1}$ de argila. No início do experimento, o solo apresentou pH 6,1 (água), $25 \mathrm{~g} \mathrm{~kg}^{-1}$ de C orgânico, 6,4 e $67 \mathrm{mg} \mathrm{dm}{ }^{-3}$ de P e K extraíveis (Mehlich) e 8,2 e 4,6 $\mathrm{cmol}_{\mathrm{c}} \mathrm{dm}^{-3}$ de $\mathrm{Ca}$ e $\mathrm{Mg}$ trocáveis, respectivamente.

O experimento vem sendo conduzido desde novembro de 2001, com delineamento experimental em blocos casualizados, com quatro repetições, em parcelas de $12 \mathrm{~m}$ x 6,3 m. Os tratamentos são: testemunha, sem adição de dejeto suíno e sem adubo solúvel (0); adubo solúvel (AS); combinação de dejeto suíno e adubo solúvel (DS); dejeto suíno aplicado nas doses de $50 \mathrm{~m}^{3} \mathrm{ha}^{-1}$ (50); $100 \mathrm{~m}^{3}$ ha $^{-1}$ (100); e $200 \mathrm{~m}^{3}$ ha $^{-1}$ (200).

O sistema de cultivo adotado envolve a sucessão de milho (Zea mays) e aveia preta (Avena strigosa), sob o sistema de semeadura direta, implantado em linhas com semeadora de disco duplo. A aplicação dos fertilizantes foi realizada para a cultura do milho, uma vez ao ano, a lanço e na superfície do solo. Os tratamentos AS e DS seguem recomendações da Comissão de Química e Fertilidade do Solo (CQFS-RS/SC, 2004). O tratamento com adubo solúvel consistiu de $140 \mathrm{~kg} \mathrm{ha}^{-1}$ de nitrogênio na forma de uréia, sendo $40 \mathrm{~kg} \mathrm{ha}^{-1}$ aplicados na semeadura, e $100 \mathrm{~kg} \mathrm{ha}^{-1} \mathrm{em}$ cobertura; $70 \mathrm{~kg} \mathrm{ha}^{-1}$ de $\mathrm{P}_{2} \mathrm{O}_{5}$ na forma de superfosfato triplo; e $100 \mathrm{~kg} \mathrm{ha}^{-1}$ de $\mathrm{K}_{2} \mathrm{O}$ na forma de cloreto de potássio. No tratamento DS foram aplicados $25 \mathrm{~m}^{3} \mathrm{ha}^{-1}$ de dejeto suíno, dose suficiente para suprir a recomendação de fósforo (70 $\mathrm{kg} \mathrm{ha}^{-1}$ ), completando-se com $80 \mathrm{~kg} \mathrm{ha}^{-1} \mathrm{de} \mathrm{N}$ em cobertura na forma de uréia, e $70 \mathrm{~kg} \mathrm{ha}^{-1}$ de $\mathrm{K}_{2} \mathrm{O}$ na forma de cloreto de potássio. $\mathrm{O}$ dejeto suíno foi gerado por animais em fase de terminação, no sistema de confinamento, sendo recolhido por canal conectado à bioesterqueira, onde permaneceu em digestão anaeróbia por aproximadamente 40 dias. A aplicação de dejeto nas doses indicadas é feita a lanço, uma vez ao ano, imediatamente antes da semeadura do milho, o que ocorre normalmente na segunda quinzena de outubro. O dejeto utilizado vem sendo analisado a cada aplicação, apresentando de 40 a $60 \mathrm{~g} \mathrm{dm}^{-3}$ de matéria seca.

As amostras de solo para análises físicas e de carbono orgânico foram coletadas nas profundidades de 0-5, 5-10 e 10-20 cm, em janeiro de 2006, três meses após a última aplicação de dejetos e da adubação, durante a fase de pendoamento da cultura do milho. Os atributos do solo avaliados foram: teores de carbono orgânico, densidade do solo, estabilidade de agregados em água, macroporosidade, microporosidade e porosidade total.

A densidade do solo foi analisada pelo método do anel volumétrico e a densidade de partículas foi avaliada pelo método do balão volumétrico (Embrapa, 1997). Os anéis utilizados tinham $5 \mathrm{~cm}$ de altura e volume de $100 \mathrm{~cm}^{3}$. A microporosidade foi determinada em mesa de tensão de areia, com sucção de $6 \mathrm{kPa}$ e a porosidade total foi calculada pela relação entre as densidades do solo e de partículas. A macroporosidade foi calculada por diferença entre porosidade total e microporosidade (Embrapa, 1997). A estabilidade de agregados foi determinada pelo método de peneiramento úmido em amostras destorroadas e tamisadas entre 4,76 e 8,35 mm, conforme método descrito por Kemper \& Chepil (1965). O carbono orgânico foi determinado após oxidação úmida com dicromato de potássio pelo método titulométrico (Tedesco et al., 1995).

Os resultados foram submetidos à análise de variância pelo teste $\mathrm{F}$, considerando-se o fator tratamento como parcela principal e profundidade como subparcela. As comparações de médias foram realizadas pelo teste $\mathrm{t}$ (LSD P<0,05).

\section{RESULTADOS E DISCUSSÃO}

Os teores de carbono orgânico no solo não foram influenciados pela adição de dejeto, sendo observada somente variação em profundidade, diminuindo de $31 \mathrm{~g}$ $\mathrm{kg}^{-1}$ na camada de 0 a $5 \mathrm{~cm}$, para $24 \mathrm{~g} \mathrm{~kg}^{-1}$ na camada de 10 a $20 \mathrm{~cm}$ (Tabela 1). O fato da aplicação de dejeto não resultar 
em incrementos nos teores de C orgânico deve-se, provavelmente, ao aumento na atividade microbiana, resultando em maior intensidade de mineralização da matéria orgânica do solo (N'dayegamiye \& Côté, 1989). Por outro lado, em trabalho realizado por Ceretta et al. (2003) com doses de 20 e $40 \mathrm{~m}^{3} \mathrm{ha}^{-1}$ de dejeto suíno, aplicadas durante quatro anos em pastagem natural, observou-se incremento nos teores de C orgânico, na camada 0 a $2,5 \mathrm{~cm}$. Resultado semelhante foi relatado por Hati et al. (2006), ao estudarem o efeito combinado da adubação mineral e resíduos animais aplicados na dose de $10 \mathrm{Mg} \mathrm{ha}^{-1}$ em um Vertisol, observando que o dejeto de suíno aumentou o carbono orgânico no solo na camada de 0 a $15 \mathrm{~cm}$, passando de 4,4 $\mathrm{g} \mathrm{kg}^{-1}$ na testemunha, para $6,2 \mathrm{~g} \mathrm{~kg}^{-1}$ com adubação mineral e dejeto animal.

A densidade do solo variou entre 1,34 e $1,50 \mathrm{Mg} \mathrm{m}^{-3}$, sem efeito de tratamento e camada (Tabela 1). Barzegar et al. (2002) aplicaram doses de esterco de curral de 0 a $15 \mathrm{Mg} \mathrm{ha}^{-1}$ e observaram diminuição na densidade e aumento na porosidade do solo. A aplicação de adubação mineral e orgânica em um Vertisol, na Índia, reduziu a densidade do solo na camada de 0 a 7,5 $\mathrm{cm}$ de $1,30 \mathrm{Mg}$ $\mathrm{m}^{-3}$ no tratamento testemunha, para $1,18 \mathrm{Mg} \mathrm{m}^{-3}$ com aplicação de esterco e adubação mineral (Hati et al., 2006). Segundo esses autores, a diminuição na densidade do solo pode estar relacionada ao papel da matéria orgânica, influenciando a porosidade do solo nos tratamentos com maior aplicação de resíduos orgânicos.

A estabilidade de agregados foi maior no solo sem adubo (DMG $=6,1 \mathrm{~mm}$ ) e decresceu das doses de 50 e 100 $\mathrm{m}^{3} \mathrm{ha}^{-1}$ de dejeto (DMG $\left.=5,7 \mathrm{~mm}\right)$. Entretanto, a redução pode ser considerada de pequena magnitude. Esse Latossolo Vermelho Distroférrico possui teores elevados de argila e óxidos de ferro (Embrapa, 2004), o que, juntamente com o teor de $\mathrm{C}$ orgânico, confere elevada estabilidade de agregados.

A distribuição de tamanhos de poros e a porosidade total do solo não foram influenciadas pelos tratamentos (Figura 1). O volume de macroporos variou entre 0,12 a $0,15 \mathrm{~m}^{3} \mathrm{~m}^{-3}$ na média das camadas. Considerando que os macroporos são a rota principal para o movimento da água e ar no solo, observa-se que os valores encontrados estão acima do nível crítico de $0,10 \mathrm{~m}^{3} \mathrm{~m}^{-3}$ (Reichert et al., 2003). Volume de macroporos inferior a esse é limitante para o desenvolvimento da maioria das culturas. A

Tabela 1 - Teores de carbono orgânico e atributos físicos de um Latossolo Vermelho distroférrico, em diferentes camadas, com doses crescentes de dejeto suíno aplicadas no período de 2001 a 2006, em área agrícola sob semeadura direta.

\begin{tabular}{|c|c|c|c|c|c|c|c|}
\hline \multirow{2}{*}{ Camada $(\mathrm{cm})$} & \multicolumn{7}{|c|}{ Tratamentos $^{(1)}$} \\
\hline & 0 & AS & DS & 50 & 100 & 200 & Média \\
\hline & \multicolumn{7}{|c|}{ Carbono orgânico $\left(\mathrm{g} \mathrm{kg}^{-1}\right), \mathrm{CV}^{(2)}=14 \%$} \\
\hline $0-5$ & 25,8 & 29,7 & 32,5 & 31,4 & 32,6 & 35,5 & $31,2 \mathrm{~A}$ \\
\hline $5-10$ & 27,6 & 27,8 & 25,3 & 23,9 & 24,2 & 27,2 & $26,0 \mathrm{~B}$ \\
\hline $10-20$ & 24,1 & 21,0 & 23,6 & 25,2 & 23,8 & 23,7 & $23,6 \mathrm{C}$ \\
\hline \multirow[t]{2}{*}{ Média } & 25,8 & 26,2 & 27,1 & 26,8 & 26,9 & 28,8 & \\
\hline & \multicolumn{7}{|c|}{ Densidade do solo $\left(\mathrm{Mg} \mathrm{m}^{-3}\right), \mathrm{CV}=5 \%$} \\
\hline $0-5$ & 1,38 & 1,42 & 1,50 & 1,43 & 1,46 & 1,41 & 1,43 \\
\hline $5-10$ & 1,47 & 1,45 & 1,46 & 1,41 & 1,44 & 1,49 & 1,45 \\
\hline $10-20$ & 1,39 & 1,43 & 1,40 & 1,46 & 1,34 & 1,41 & 1,40 \\
\hline \multirow[t]{2}{*}{ Média } & 1,41 & 1,44 & 1,45 & 1,43 & 1,41 & 1,44 & \\
\hline & \multicolumn{7}{|c|}{ Diâmetro médio geométrico (DMG) dos agregados $(\mathrm{mm}), \mathrm{CV}=6 \%$} \\
\hline $0-5$ & 6,1 & 6,0 & 6,0 & 5,6 & 5,4 & 5,6 & 5,8 \\
\hline $5-10$ & 6,3 & 6,1 & 5,9 & 5,9 & 6,0 & 6,0 & 6,0 \\
\hline $10-20$ & 6,0 & 5,9 & 6,1 & 5,7 & 5,6 & 6,0 & 5,9 \\
\hline Média & $6,1 \mathrm{a}$ & $6,0 \mathrm{ab}$ & $6,0 \mathrm{ab}$ & $5,7 \mathrm{bc}$ & $5,7 \mathrm{c}$ & $5,9 a b c$ & \\
\hline
\end{tabular}

1. Tratamentos: 0: testemunha; AS: adubo solúvel; DS: combinação de dejeto e adubo solúvel; 50, 100 e 200: doses de dejeto suíno $\left(\mathrm{m}^{3} \mathrm{ha}^{-1}\right)$. Médias seguidas pela mesma letra maiúscula na coluna, e minúscula, na linha são iguais pelo teste $\mathrm{t}(\mathrm{DMS}, \mathrm{P}<0,05)$. Somente foram indicadas as comparações significativas. CV: coeficiente de variação. 
microporosidade variou de 0,32 a $0,34 \mathrm{~m}^{3} \mathrm{~m}^{-3}$ na média das camadas. Deve-se considerar que outros fatores, além da forma e quantidade de adubação, podem influenciar a qualidade física do solo, especialmente decorrentes do menor revolvimento do solo no sistema de semeadura direta, além dos efeitos do sistema radical das plantas, em termos de porosidade e agregação (Silva et al., 2005).

A porosidade total também não diferiu significativamente entre os tratamentos e camadas analisadas (Figura 1). A porosidade total variou de 0,45 a $0,48 \mathrm{~m}^{3} \mathrm{~m}^{-3}$ na média das camadas. Hati et al. (2006) observaram aumento da porosidade total, quando combinada adubação mineral com esterco de curral, em relação ao tratamento testemunha. Pagliai et al. (1983) observaram que a aplicação de dejeto suíno, na dose de $300 \mathrm{~m}^{3} \mathrm{ha}^{-1}$, aumentou a porosidade total de 0,10 para 0,31 $\mathrm{m}^{3} \mathrm{~m}^{-3}$ principalmente pela participação de poros maiores que 30 micras de diâmetro, na camada superficial de um solo argilo-siltoso. Os mesmos autores observaram que a forma dos poros também foi alterada. A incorporação do esterco diminuiu a formação de poros maiores que 500 micras de formato alongado e aumentou os de formato redondo ou irregular. Trabalho realizado por Seganfredo (1998), indicou que as doses de dejeto suíno calculadas para suprir entre 100 e $150 \mathrm{~kg} \mathrm{ha}^{-1}$ de nitrogênio diminuíram a microporosidade e a densidade do solo, e aumentaram a macroporosidade e a porosidade total do solo, sendo esses efeitos evidenciados somente após o terceiro ano de aplicação.

A análise conjunta dos atributos físicos evidencia alta estabilidade da estrutura, mas valores relativamente elevados de densidade do solo para a classe textural desse Latossolo, quando se considera a qualidade estrutural do solo para o desenvolvimento das raízes e produtividade das plantas (Reichert et al., 2003). Por outro lado, a relação entre macroporosidade e densidade do solo permite estabelecer densidade crítica de $1,56 \mathrm{Mg} \mathrm{m}^{-3}$, para atingir macroporosidade de $0,10 \mathrm{~m}^{3} \mathrm{~m}^{-3}$ (Figura 2).

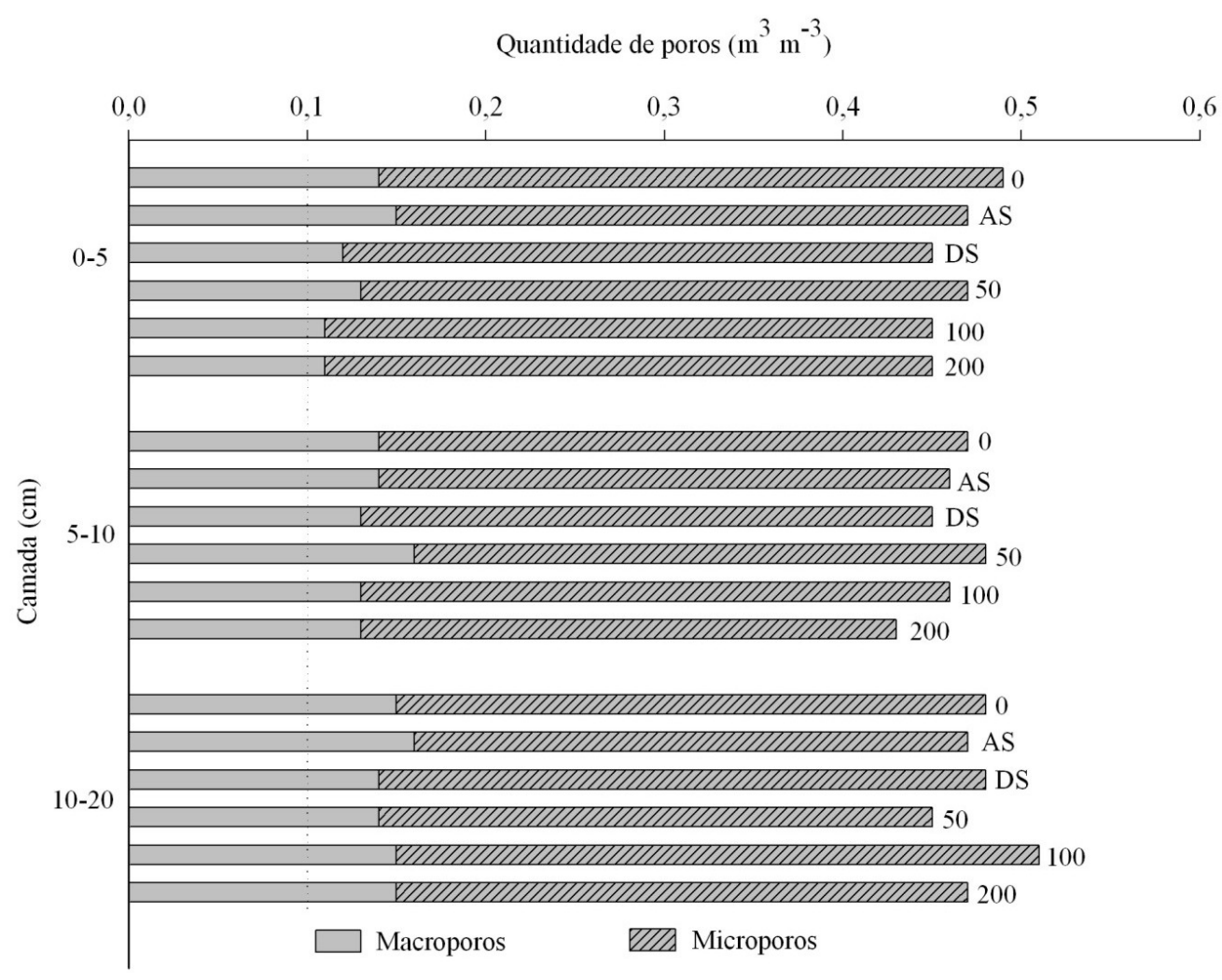

Figura 1 - Distribuição de poros de um Latossolo Vermelho distroférrico, em diferentes camadas, com doses crescentes de dejeto suíno aplicadas no período de 2001 a 2006, em área agrícola sob semeadura direta. Tratamentos: 0: testemunha; AS: adubo solúvel; DS: combinação de dejeto e adubo solúvel; 50, 100 e 200: doses de dejeto suíno $\left(\mathrm{m}^{3}\right.$ ha-1). 


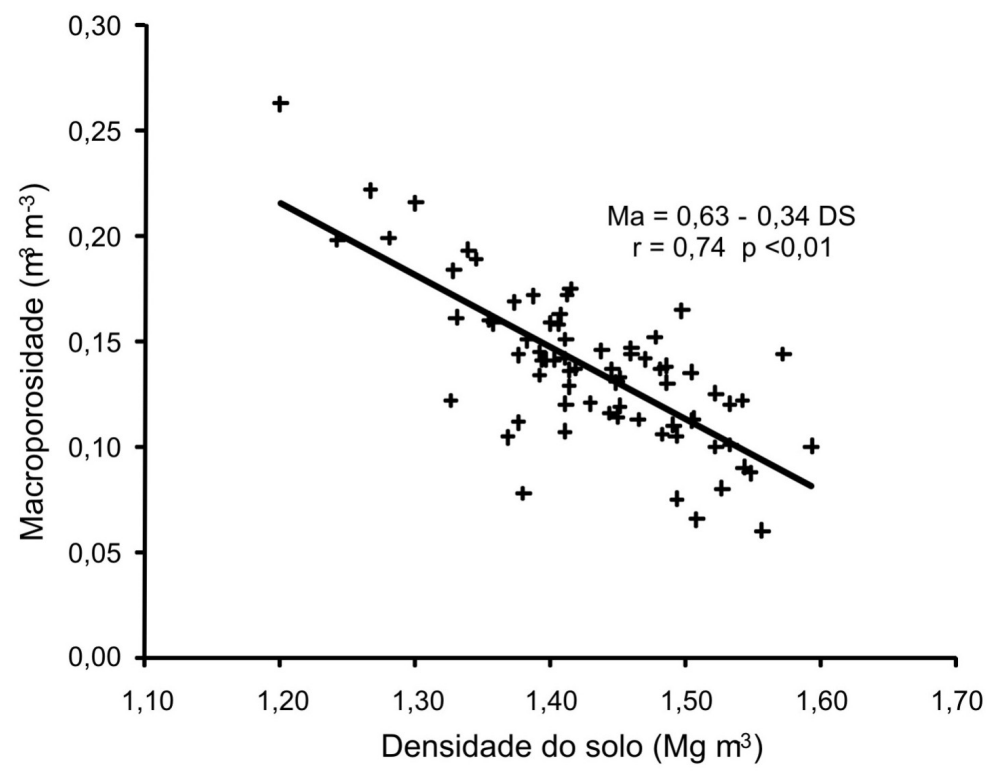

Figura 2 - Relação entre densidade do solo e macroporosidade de um Latossolo Vermelho distroférrico, com doses crescentes de dejeto suíno aplicadas no período de 2001 a 2006, em área agrícola sob semeadura direta $(\mathrm{n}=72)$.

\section{CONCLUSÕES}

A aplicação de dejeto suíno nas doses de 50 e 100 $\mathrm{m}^{3} \mathrm{ha}^{-1}$ reduziu a estabilidade de agregados do solo, em relação ao tratamento testemunha sem adubação. Os demais atributos físicos do solo e o teor de $\mathrm{C}$ orgânico não foram modificados pelos tratamentos, indicando que o uso agrícola do dejeto suíno, nas condições estudadas, mantém a qualidade física do solo.

\section{REFERÊNCIAS BIBLIOGRÁFICAS}

BARZEGAR, A.R.; YOUSEFIL, A.; DARYASHENAS, A. The effect of addition of different amounts and types of organic materials on soil physical properties and yield of wheat. Plant and Soil, Dordrecht, v.247, n.2, p.295-301, 2002.

CERETTA, C.A.; DURIGON, R.; BASSO, C.J.; BARCELLOS, L.A.R.; VIEIRA, F.C.B. Características químicas de solo sob aplicação de dejeto líquido de suínos em pastagem natural. Pesquisa Agropecuária Brasileira, Brasília, v.38, n.6, p.729-735, 2003.

COMISSÃO DE QUÍMICA E FERTILIDADE DO SOLO. Sociedade Brasileira de Ciência do Solo. Manual de adubação e de calagem para os estados do Rio Grande do Sul e Santa Catarina. 10.ed. Porto Alegre: SBCS/NRS, 2004. 400p.

\section{EMPRESA BRASILEIRA DE PESQUISA}

AGROPECUÁRIA. Centro Nacional de Pesquisa de Solo. Manual de métodos de análise de solo. 2.ed.

Brasília: Embrapa Produção de informações; Rio de Janeiro: Embrapa Solos, 1997. 212p.

\section{EMPRESA BRASILEIRA DE PESQUISA}

AGROPECUÁRIA. Centro Nacional de Pesquisa de Solo. Solos do Estado de Santa Catarina. Rio de Janeiro, 2004. 726p. (Boletim de pesquisa e desenvolvimento, 46).

HATI, K.M.; MANDAL, K.G.; MISRA, A.K.; GHOSH, P.K.; BANDYOPADHYAY, K.K. Effect of inorganic fertilizer and farmyard manure on soil physical properties, root distribution, and water-use efficiency of soybean in Vertisols of central India. Bioresource Technology, Oxford, v.97, n.16, p.2182-2188, 2006.

JOKELA, W.E.; GRABBER, J.H.; KARLEN, D.L.; BALSER, T.C.; PALMQUIST, D.E. Cover crop and liquid manure effects on soil quality indicators in a corn silage system. Agronomy Journal, Madison, v.101, p.727-737, 2009.

KEMPER, W.D.; CHEPIL, W.S. Size distribution of aggregates. In BLACK, C.A.; EVANS, D.D.; WHITE, J.L. (Eds.). Methods of soil analysis. Madison: American Society of Agronomy, 1965. p.499-510. (Agronomy, Monography, 9). 
MOSADDEGHI, M.R.; MAHBOUBI, A.A.; SAFADOUST, A. Short-term effects of tillage and manure on some soil physical properties and maize root growth in a sandy loam soil in western Iran. Soil and Tillage Research, Amsterdam, v.104, p.173-179, 2009.

N'DAYEGAMIYE, A.; CÔTÉ, D. Effect of long term pig slurry and solid cattle manure application on soil chemical and biological properties. Canadian Journal of Soil Science, Ottawa, v.69, n.1, p.39-47, 1989.

OLIVEIRA, P.A.V. Manual de manejo e utilização dos dejetos de suínos. Concórdia: Embrapa Suínos e Aves, 1993. 188p. (Documento, 27).

PAGLIAI, M.; BISDOM, E.B.A.; LEDIN, S. Chances in surface structure (crusting) after application of sewage sludge and pig slurry to cultivated agricultural soils in northern Italy. Geoderma, Amsterdam, v.30, n.1, p.35-53, 1983.

REICHERT, J.M.; REINERT, D.J. BRAIDA, J.A. Qualidade dos solos e sustentabilidade de sistemas agrícolas. Ciência \& Ambiente, Santa Maria, n.28, p.2948, 2003.

RIBEIRO, K.D.; MENEZES, S.M.; MESQUITA, M.G.B.F.; SAMPAIO, F.M.T. Propriedades físicas do solo, influenciadas pela distribuição de poros, de seis classes de solos da região de Lavras-MG. Ciência e

Agrotecnologia, Lavras, v.31, n.4, p.1167-1175, 2007.

SCHERER, E.E.; BALDISSERA, I.T.; DIAS, L.F.X.

Potencial fertilizante do esterco líquido de suínos da região Oeste Catarinense. Agropecuária Catarinense, Florianópolis, v.8, n.2, p.35-39, 1995.

SEGANFREDO, M.A. Efeito de dejetos líquidos de suínos sobre algumas características físicas do solo. In: REUNIÃO SUL-BRASILEIRA DE CIÊNCIA DO SOLO,

2., 1998, Santa Maria. Anais... Santa Maria: Sociedade Brasileira de Ciência do Solo, 1998.

SEGANFREDO, M.A. Uso de dejetos suínos como fertilizantes e seus riscos ambientais. In: Gestão ambiental na suinocultura. Brasília: Embrapa Informação Tecnológica, 2007. p.149-175.

SILVA, R.R.; SILVA, M.L.N.; FERREIRA, M.M.

Atributos físicos indicadores da qualidade do solo sob sistemas de manejo na bacia do alto do Rio Grande,

MG. Ciência e Agrotecnologia, Lavras, v.29, n.4, p.719730, 2005.

TEDESCO, M.J.; GIANELLO, C.; BISSANI, C.A.; BOHNEN, H.; VOLKWEISS, S.J. Análises de solo, plantas e outros materiais. 2.ed. Porto Alegre: UFRGS, 1995. 174p. (Boletim técnico de solos, 5). 